In print. To appear in: Patrick Colm Hogan, Bradley J. Irish, and Lalita Pandit Hogan, ed. The Routledge Companion to Literature and Emotion. London: Routledge 2021.

\title{
AESTHETIC EMOTIONS
}

\author{
Sibylle Baumbach
}

https://orcid.org/0000-0003-2616-9077

\begin{abstract}
Not all emotions experienced in the encounter with literature are 'aesthetic'. As suggested by the seeming paradox inherent in the term 'aesthetic emotions', the latter embraces reactive and reflective responses, combining emotional and cognitive processes in the appreciation of a literary text, and includes some conceptual tension. Following a brief survey of recent research in the field, this chapter explores fascination as aesthetic emotion, proposing that the latter can be conceived as mixed emotions which push our emotional repertoire to its limits, create instances of emotional and cognitive disorientation, and prompt temporary in/securities of attachment which ultimately contribute to the pleasure arising from coping with these complex emotions in the process of reading. It further suggests that due to its focus on mixed emotions and the sublime, the Gothic genre in particular affords aesthetic emotions.
\end{abstract}

Keywords: aesthetic emotions, fascination, Gothic fiction, sublime, attachment-detachment

\section{Approaching Aesthetic Emotions: Coming to Terms with a Paradox}

Considering that our classification systems are binary in nature, the simplest way to define aesthetic emotions would be to oppose them to 'non-aesthetic' emotions. As such, they would denote emotions that are aesthetically generated, meaning that they emerge in the appreciation of aesthetic objects or textures, including artworks, design objects, literary texts, or music. With recourse to Immanuel Kant's concept of 'disinterested pleasure', aesthetic emotions might be further specified as a non-utilitarian sensual pleasure felt particularly in the experience of beauty, including beauty in nature. One might also conceive of 'aesthetic emotions' as the opposite of 'ethical' or 'moral' emotions, connecting to the key principle of Aestheticism, l'art pour l'art, which aims at uncoupling the appreciation of beauty from any moral considerations, as propagated, for instance, in Joris-Karl Huysman's novel À Rebours (1884) or the writings of Oscar Wilde. Further, 'aesthetic' emotions might be juxtaposed to 'real' emotions, in that they are imagined, even irrational.

There are several limitations to these binary classifications. First, they lack precision: 'Aesthetic emotions' in the sense outlined above seems to be interchangeable with 'aesthetic 
pleasure' or 'aesthetic experience' which, in classical aesthetic theory, is associated with a sense of pleasurable fulfilment. Aesthetic responses to literature, however, include a variety of emotions which are not necessarily pleasurable. Furthermore, the opposition of 'aesthetic' and 'non-aesthetic' emotions, such as "boredom" or "frustration/anger" (Hogan 113), might suggest that aesthetic emotions are "refined emotions" (Frijda/Sundararajan 231). This notion has been challenged by Jenefer Robinson who argues that "refined emotions aren't emotional at all", as they are "perceptual rather than emotional" $(2020,210)$.

Second, if restricted to the experience of 'disinterested' sensual pleasure or morally neutral emotions, the category of aesthetic emotions is suitable only to a limited extent for a deeper investigation of the complex emotional landscape elicited by literature: It would fail to account for 'negative' aesthetic emotions such as disgust (Robinson 2014) or 'knowledge emotions', such as confusion, interest, surprise and awe, which "stem from goals associated with learning" (Silvia 2010, 75) and include metacognitive processes. It would also fail to accommodate mixed emotions, such as feelings of the sublime or fascination, and emotions related to the moral disapproval of fictional characters or events, as experienced, for instance, in tragedy (Feagin). Furthermore, aesthetic emotions might arise from morally questionable aesthetic experiences provoked, for instance, by narratives that draw on readers' fascination with moral transgression to seduce them into storyworlds filled with taboo topics, such as incest, paedophilia, rape, or pornography, which is a key strategy of Ian McEwan's aka 'Ian Macabre's early narratives (cf. Baumbach 240-251).

Third, as research in the context of 'the paradox of fiction', especially with regard to simulation theory, has shown (see Hogan, "Paradoxes of Literary Emotion" in this volume), the emotions we feel in response to fictional events and characters are genuine (Oatley 1999) even if, as part of literary thought experiments, they might differ from real-life emotions with regard to their cognitive base.

Defining aesthetic emotion remains a challenge. While in recent years, a number of studies have attempted to conceptualise aesthetic emotions from the perspective of philosophy (Robinson, esp. “Aesthetic Emotions”), psychology (Beermann et al.), neuroaesthetics (Zeki), and empirical aesthetics (Menninghaus et al.), aesthetic emotions are still often "neglected" (Elpidorou) in emotion theory. One of the reasons for this neglect might be the conceptual tension inherent in the term. Combining two highly complex concepts, perception (the core meaning of the Greek term 'aesthetics') and emotion, 'aesthetic emotion' is ultimately a paradox, even "an oxymoron” (Robinson 2020, 205). 
As noted by Robinson, "[t]he paradox of aesthetic emotions" is that "the aesthetic is defined by Kant and his many successors as contrasting with practical goals" $(2020,208)$. Whereas practical goals and desires might vary between different people, Kantian aesthetics regards aesthetic pleasure as universal, which is why it must be 'disinterested'. Though one could argue that aesthetic emotions are non-utilitarian to the extent that they are "produced by the appreciation of the intrinsic qualities of the beauty of nature, [...] of a work of art or an artistic performance" (Scherer 706), emotions are essentially subjective and "may be oriented to good, bad, or indifferent ends" (Hogan 5).

As further observed by Robinson, if "the most valuable aesthetic experiences are often perceptually or cognitively demanding, [...] aesthetic emotions would presumably follow after the cognitive analysis of an artwork is complete but not contribute in any substantive way to the analysis itself" (Robinson 2020, 205-206). In this understanding, however, aesthetic emotions would merely serve as an (unnecessary) add-on, or, as Robinson remarks, "[t]he aesthetic emotions would be otiose" (206).

To further conceptualise aesthetic emotions, especially in connection with literature, I will first offer a brief survey of current research in this field, which confirms that aesthetic emotions are anything but "otiose", before focusing on fascination as aesthetic emotion and proposing a multidimensional approach to the concept, which also opens up new areas for future research.

\section{Conceptualising Aesthetic Emotions}

In recent scholarship, aesthetic emotions have been defined as "full-blown discrete emotions that, for all their differences in multiple emotion components, always include an aesthetic evaluation/appreciation" (Menninghaus et al. 2019, 171), as "blends of emotion terms with additional meanings of aesthetic evaluation" (Menninghaus et al. 2020,651), and as comprising “emotional complexity (or ambivalence)" (Hogan 232).

Recent studies in empirical aesthetics have proposed various tools for future research on aesthetic emotion, such as the Aesthetic Emotions Scale (AESTHEMOS) developed by Schindler et al. to assess aesthetic emotions based on 75 emotion terms. Though rather broad in scope, covering not only the arts but also experiences in nature and other contexts of aesthetic appreciation, Schindler et al.'s definition is the most comprehensive to date: They conceive of aesthetic emotions as emotions that (1) "recipients actually feel"; (2) are non-utilitarian in that they are elicited through "the intrinsic aesthetic appeal of a stimulus"; (3) are triggered through 
"the distance senses", i.e. "vision, hearing, and cognitive processing in response to such input", (4) are "intertwined with aesthetic judgement" (Schindler et al. 2-3), and (5) are "distinct from pleasing emotions, epistemic emotions [i.e. what Silvia calls 'knowledge emotions'], and negative emotions" (Schindler et al. 28). Based on this taxonomy, they identify four "prototypical aesthetic emotions": "(1) the feeling of beauty/liking ${ }^{1},(2)$ fascination, (3) being moved, and (4) awe" (28). For the study of literature or film, they also suggest to consider feelings of suspense or thrill, even though one could argue that these are to some extent covered by the AESTHEMOS 'fascination' subscale (cf. Schindler et al. 33).

What is a crucial in Schindler et al.'s conceptualisation of aesthetic emotions, which was confirmed by studies of the semantic profile of aesthetic emotion terms (Beermann et al. 16), is the observation that aesthetic emotions are complex emotions, which "often involve mixtures of positive and negative valence and can be experienced as both arousing and relaxing" (Schindler et al. 26). This finding, which corresponds to the paradox inherent in the term, suggests that the combination of seemingly contrastive components is no obstacle to defining aesthetic emotions, but rather marks their core.

It is particularly due to these recent studies in empirical aesthetics as well as to Jenefer Robinson's work that research on aesthetic emotions has been gaining traction. Robinson classifies aesthetic emotions as "positive, pleasurable, consummatory emotions [...] of appreciation" $(2020,205)$, which are non-instrumental to the extent "that they have specific types of intentional object, namely the formal interrelationships in an artwork as well as the relationship between form and content" (219) and "do not motivate any specific behavior, except continuing to engage in the pleasurable contemplation of the artwork" (213). Furthermore, she claims that aesthetic emotions are to some extent self-sustaining, as they "motivate us to seek further sources of such satisfaction in other artworks" (219). This is in line with both Kantian aesthetics and recent empirical findings which suggest that aesthetic emotions "may motivate a wish to seek prolonged and repeated exposure [...] to a beautiful stimulus" (Menninghaus et al. 2019, 185), even though the term 'beautiful' in this context seems too restrictive.

Though too narrow to define the concept, the role of "formal interrelationships in an artwork" in eliciting aesthetic emotions, as maintained by formalist art theory, is an important notion to consider. It was first proposed by Clive Bell in his influential monograph Art (1914),

\footnotetext{
1 'Beauty' and 'liking' were combined, as the study was conducted in German, and the German term schön both denotes something beautiful and indicates liking (cf. Schindler et al. 29).
} 
which introduced the term 'aesthetic emotion'2 and is still an important reference point for contemporary approaches on aesthetic experience. Bell suggested that aesthetic emotion is "a particular kind of emotion provoked by works of visual art" (6-7) through "Significant Form" (8). The latter refers to "aesthetically moving forms", i.e. "relations and combinations of lines and colours"(8), which have been devised by the artist following "certain unknown and mysterious laws" (11). Opposing the premises of realism, such as "accurate representation" (22), 'significant form', which can be found in "primitive art" (22) or Post-Impressionist art, is "free from descriptive qualities" (22). However, beyond 'significant form' Bell does not identify any specific configurations that trigger aesthetic emotions. Further, he concedes that "aesthetic emotions vary with each individual" (9). Countering Bell's notion that aesthetic responses are largely subjective, neuroaesthetic studies have tried to isolate mechanisms in "the emotional brain" (Zeki 11) that are activated in the experience of beauty and universal insofar as they are "to a large extent biologically determined" (Zeki 5). Identifying specific patterns or features that arouse aesthetic emotion, however, remains a challenge for art history, musicology, and (cognitive) literary studies.

A purely formalist approach is unproductive for the study of literature since form and content are intimately intertwined and aesthetic emotions are contingent on one's cognitive grasp of a work (Robinson 2020,212). And yet Bell's approach raises the question of whether there are any specific literary 'forms' or techniques that afford aesthetic emotions. Considering that Bell was part of the Bloomsbury group, the narratives by Virginia Woolf might come to mind not only because she shared Bell's deep interest in aesthetic theories, but also because her stream-of-consciousness technique connects to the "aesthetically moving forms" and the "relations and combinations" in Bell's theory. Furthermore, Woolf's narratives are concerned with feelings of beauty and sublimity (Hogan 25), which are or involve ('awe') prototypical aesthetic emotions. The "terror of existential loneliness" (Hogan 45) expressed in Mrs Dalloway (1925), for instance, is represented and, to some extent, also contained by both sublimity and the unity across individual minds in the experience of beauty. As a result, the narrative creates securities and insecurities about attachment which Hogan has identified as "the most important emotion component" (45) in aesthetic response. In terms of form, these in/securities about attachment seem to be most effectively evoked through techniques of

\footnotetext{
${ }^{2}$ Some critics have suggested that Bell's use of the term is "unfortunate", as his theory of aesthetic experience follows a perceptual rather than an emotive model (Gould, 126; Zeki).
} 
psychological realism, including stream of consciousness and first-person narration, which might therefore be regarded as fostering aesthetic emotions.

If we broaden our understanding of literary form to include literary genre as 'bounded whole' (Levine 23), the Gothic seems a particularly apt 'form' to elicit aesthetic emotion: Gothic literature combines a variety of positive and negative emotions while building on tensions between beauty and sublimity, which create various attachment in/securities. These tensions characterise the complex emotional landscape of the Gothic, which revolves around the prototypical aesthetic emotion of fascination.

\section{Fascination as Aesthetic Emotion}

As suggested by Schindler et al. and earlier studies in literature (Baisch) and psychology (Marcovic), fascination is a key aesthetic emotion. It belongs to the category of mixed emotions which arise in "the simultaneous or nearly simultaneous co-occurrence of relatively brief positive and negative affective states" (Larsen et al. 2) in the experience of a complex event. These mixed or complex emotions are particularly prominent in the realm of the aesthetic, afforded by the potentialities of literature and art. As suggested by Korsmeyer in relation to aesthetic emotions, "[w]ith certain emotions [...] aesthetic transformation is so profound that an entirely new affective experience is brought into being" (Korsmeyer 130). In the experience of the sublime, for instance, terror is "transmogrified into powerful and transportive aesthetic delight" (133). Something similar can be claimed for fear or repulsion in the context of fascination, insofar as these negative emotions are coupled with knowledge emotions such as curiosity or attraction, producing aesthetic pleasure. By creating an arena for mixed emotions, therefore, literary works "enlarg[e] our repertoires of emotional states" (Robinson 2020, 81). In this context, fascination is particularly productive.

Fascination has been associated with admiration and awe (Scherer 714) and placed on the emotional spectrum between admiration and stupor (Degen 38). In this sense, it is deeply connected to the feeling of the sublime, which, following Edmund Burke's definition, "is productive of the strongest emotion which the mind is capable of feeling" (Burke 33-34), insofar as the sublime includes the experience of awe which arises from a combination of "terror and at the same time admiration or reverence for its "terribleness"” (Robinson 2014, 74). Connecting to the crucial role of attachment in aesthetic response, one could conceptualise fascination as the tension between simultaneous desires for de- and attachment which arise from conflicting responses, such as attraction and fear or repulsion. This conflict creates 
cognitive disorientation, which upsets familiar attachment strategies, but ultimately - by involving self-reflexive elements and distancing which enables cognitive coping (cf. Lazarus 112f.) - intensifies the attachment to a specific narrative.

Mary Shelley's Frankenstein, or The Modern Prometheus (1818/1831) is a case in point. In the narrative, the tension between de- and attachment, underscored by allusions to (pseudo-)scientific powers of magnetism and mesmerism (cf. Baumbach, chapter 4), contributes significantly to eliciting feelings of fascination and is played out on several levels. First and foremost, it characterises the relationship between Victor Frankenstein, the lone scientist, and his creation. Whereas Victor tries to become and stay detached from his creation, the latter, abandoned by his creator and shunned by the world, is desperately seeking attachment to other human beings, the cottagers, his creator, and his own species, assuming that "one as deformed and horrible as myself would not deny herself to me" (Shelley 146). Victor's refusal to create this "companion" leads to tormenting 'terror of existential loneliness' both on the part of the creature and Frankenstein, culminating in Victor's loss of his wife Elizabeth (cf. 200-201). This attachment-detachment scenario is underscored by the frame narrative, which features another lone scientist, the "deeply affectionate" explorer Robert Walton, who is enticed by a quest for "wonders and [...] beauty" and "undiscovered solitudes" (15), while longing for "the company of a man who could sympathise with me; whose eyes would reply to mine" (19), which he does and does not find in Victor and his reader(s), be it his sister Margaret or readers of the novel.

The narrative is deeply invested in eliciting and also exploring aesthetic emotions. Frankenstein's initial reaction to the request of creating another being that might resemble the "creature of fine sensations" that he experiences his creation to be, after the latter's emotional plea for a companion, denotes a prototypical aesthetic emotion: "I was moved" (Shelley 148) - an emotion which leads to both attachment ("I compassioned him", 149) and repulsion ("but when I looked upon him, [...] my feelings were altered to those of horror and hatred", 149). This mixed reaction that Victor himself deems "strange" (149) creates the fascination with the creature, which is shared by both Victor and Shelley's readers.

The 'strangeness' Victor experiences is a crucial component to aesthetic emotions. As suggested by Keith Oatley, art and literature tend to focus on emotions that are "the most difficult to understand, which therefore need the most exploration, and which can have the most far-reaching implications for us" (Oatley 2017, 37). They are also the most difficult emotions to manage. Emotional exploration and management are tasks that are intimately 
connected with aesthetic emotions. As noted by Robinson, "the greatest artworks [...] encourage their audiences to monitor their emotional responses cognitively" (Robinson 2014, 82) and guide us "in how to reflect on the emotions we are experiencing, whether they are justified or not, and what it is about the work that has made us react in this way" (82). In the narrow definition proposed in this chapter, aesthetic emotions often push our emotional repertoire to its limits, augmenting our knowledge particularly of mixed emotions. At the same time, they include metacognitive nudges in that they motivate readers to reflect upon and monitor their emotional experiences.

This is achieved by creating a sense of safe readership which, unlike "psychical distance" (Bullough 95), requires and, to some extent, also enables intense emotional engagement. In the case of Frankenstein, distancing is facilitated through the epistolary form and the Chinese-box-structure of the narrative, which reveals the creature's story as thrice removed (retold by Victor and Walton). Both measures of distancing intensify our fascination with the narrative. From its outset, we as readers are breaking a taboo in engaging in a story that, communicated in private letters by Walton to his sister, we are not meant to read. This suggested distance, however, is compromised in the course of the narrative, as the epistolary form becomes increasingly backgrounded, leaving readers more exposed to experiences of the sublime mediated by Victor, and especially to the fascination exerted by the creature. However, it is (re-)established at the very ending: The narrative closes with the term "distance" (Shelley 225), as if to release readers from their intense engagement in this narrative.

This mode of distancing, which connects to the distancing-embracing model by Menninghaus, Wagner et al. insofar as it enables readers "to positively embrace the experiencing of negative emotions" $(2017,1)$ is a crucial component of "narratives of fascination'. As I have argued elsewhere (Baumbach esp. 24-35), these narratives involve readers cognitively and emotionally in intense emotional (and often morally ambiguous) tensions and revolve around fascination. I define fascination as a mixed emotion that combines feelings of attraction and fear or attraction and repulsion - a combination which is best represented in the figure of the Medusa, which is why I have also referred to these narratives as medusamorphoses (Baumbach 67-70). Insofar as these narratives guide readers' fascination, display examples of emotional excess (but also coping strategies), and disclose key mechanisms of fascination, they offer tools for emotion management, which support readers' understanding of key strategies involved in narrative seduction and of fascination as aesthetic emotion, its arousal, sustainment, and release. 
It is by means of strategic distancing that readers can enjoy the 'terror of existential loneliness' which drives Shelley's Frankenstein. As epistolary novel, the narrative presents, enacts, and overcomes this loneliness: It puts the reader into the position of a silent (and lonely) witness of private accounts, allowing them to (cognitively and emotionally) engage in letters written by the solitary Walton to his sister, which include confessional tales by Frankenstein and his creature. These accounts in turn display the 'terror of existential loneliness' experienced by the eccentric scientist and the abandoned creation respectively - a terror that is both acknowledged and overcome by feelings of the sublime and fascination.

Victor not only experiences but comments on aesthetic emotions that arise in his encounters with both the creature and the grandeur of the Alps, with man-made 'artwork' and nature respectively. Experiences of the sublime, such as the "beautiful yet terrific" tempest (Shelley 77) or "the sight of the awful and majestic in nature" (100), help prepare Victor for the appearance of the creature $(77 ; 102-103)$. The creature, on the other hand, though (conceptually) a product of the sublime (i.e. born out of Victor's experience of awe when observing the power of natural electricity during a thunderstorm [Shelley 42]) emerges as an object designed as "beautiful" but met with "breathless horror and disgust" (58) when it first comes to life. This seemingly contradictory response foreshadows the mixture of attraction and repulsion that will be associated with the "monster" (61) once he tells his own story - a story presented in such delicate and beautiful manner that even Victor is moved (148).

Though Victor unmistakably experiences feelings of the sublime, the sublime itself is not explicitly identified as such until the second volume of the narrative where its effect is explained: "These sublime and magnificent scenes afforded me the greatest consolation that I was capable of receiving. They elevated me from all littleness of feeling [...], gave wings to the soul, and allowed it to soar from the obscure world to light and joy" (99-100). Such instances of reflected aesthetic appreciation appeal to readers' emotional (and cognitive) response-ability while exposing the reactive and reflective aspect (Cupchik) of aesthetic emotions. They further suggest that emotions are precognitive, but need cognitive work to be fully savoured (and to become aesthetic emotions), which makes 'coping' with these complex emotions and their 'reward' all the more pleasurable. This is confirmed in the creature's account, which reiterates the initial, reactive state of experiencing "sensations of a peculiar and overpowering nature: [...] a mixture of pain and pleasure" (Shelley 111) and, in a reflective mode, connects them to "the science of words or letters" (112), to literary works, which "opened before me a wide field for wonder and delight" (122) and caused "strange feelings" 
(122). What is hinted at here is literature's ability to expand our emotional repertoires by eliciting (and also reflecting upon) awe-inspiring, often ambivalent emotions, such as fascination. Furthermore, as suggested by the creature who spends his days "in close attention" (121), fascination might help (re-)calibrate one's attentional focus, which is needed for coping with mixed emotions and experiencing aesthetic pleasure.

Extrapolating from these observations regarding fascination, aesthetic emotions can be defined as emotions which are carefully monitored and managed by narrative or poetic strategies that often operate on the verge of emotional excess while offering a sense of safe readership to open up a space for experimenting with 'strange', i.e. predominantly mixed, emotions.

\section{Towards a Multidimensional Model of Aesthetic Emotions in Literature}

Part of the difficulty of defining aesthetic emotions lies in the different levels upon which they are experienced in the encounter with literary texts. In this final section, I propose a multidimensional framework for conceptualizing aesthetic emotions, which also considers the aesthetics of production and the need for historicising aesthetic emotions.

In addition to reader-oriented perspectives, production-oriented perspectives can offer important insights into the way in which specific forms or literary genres afford aesthetic emotions. First studies in this direction have suggested that there are six emotional arcs that underlie conventional plot developments, including “"Tragedy', or 'Riches to Rags' (fall)" or “"Icarus' (rise-fall)" (Reagan et al.). Interestingly, only one of them, "Rags to riches (rise)", shows a sustained focus on the emotion happiness. This finding corroborates the notion that, more often than not, aesthetic emotions involve negatively valanced emotions, which "secure attention, intense emotional involvement, and high memorability" (Menninghaus et al. 2017, $3)$.

To some extent, we should regard aesthetic emotions as genre-dependent. Considering that particularly the Romantic era saw a heightened interest in the ability of literature and art to express emotions, literary forms and genres popular at the time are fruitful starting points for investigating aesthetic emotions in literature. Furthermore, according to Romantic aesthetics, it is by expressing emotions that they can be brought into consciousness, which enables their understanding, monitoring and mastery both in the process of reception and poetic creation. This is suggested in William Wordsworth's often-cited aesthetic credo that "Poetry is the spontaneous overflow of powerful feelings: it takes its origin from emotion recollected in 
tranquillity: the emotion is contemplated till by a species of reaction the tranquillity gradually disappears, and an emotion, similar to that which was before the subject of contemplation, is gradually produced, and does itself actually exist in the mind" (Wordsworth 266). It was Wordsworth, therefore, who offered one of the earliest definitions of aesthetic emotions. While he is specifically referring to aesthetic emotions in connection with poetry - and popular poetic forms in Romanticism, such as the elegy or ode, would lend themselves to a deeper analysis in this context -, in my view it is the Gothic genre which most affords aesthetic emotions, such as fascination, induced by terror, horror, or feelings of the sublime.

Like all emotions, aesthetic emotions are "socially situated, adaptive, trained, plastic, and thus historical" (Scheer 193). Insofar as they are shaped by "emotional communities" (Rosenwein) and conventions of "emotional styles" (Gammerl) established by authors, literary works, and their readers at a particular time, aesthetic emotions show historical variations. This is confirmed by the shifting meanings of fascination, which developed from contexts of black magic (from Latin fascinare - 'to becry, bewitch') to predominantly positive connotations in contemporary culture. Even though as aesthetic emotion fascination might show little variation across time and has largely retained its complexity and ambivalent tension, to understand the nuances in its literary use and effect it is essential to consider the socio-cultural and aesthetic discourses surrounding 'fascination' in a specific period.

Thus, it is quite likely that an Early Modern audience of Shakespeare's Macbeth (1606), which associated fascination with the evil eye, pseudo-scientific theories of love, or the spreading of diseases by invisible spirits that travelled through the air, responded slightly differently to the attachment, emotion management, and coping strategies offered by the play

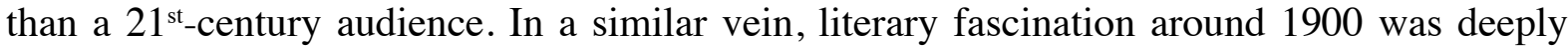
embedded in the shift from the moral, epistemic, and educational function of literature to a focus on aestheticism and decadence. This is important in relation to fascination as aesthetic emotion in Oscar Wilde's The Picture of Dorian Gray (1890), for instance. Finally, readers acquainted with prospects of the posthuman (recently explored in Jeanette Winterson's Frankissstein [2019]), and (potentially) less familiar with the aesthetics of the sublime, might experience the creation scene and simulations of the sublime in Shelley's Frankenstein differently than early $19^{\text {th }}$-century readers who eagerly followed the progress of Galvanism. While it is impossible to revive historical readers, we have to be aware of the historical embeddedness of aesthetic emotions and their historical emplotment within narratives. 
In addition to considering the affordances of specific literary forms and genres as well as individual and historical variabilities of aesthetic emotions, an analysis of aesthetic emotions in literature needs to distinguish between paratextual, textual, intratextual, and intertextual or intermedial aesthetic emotions to acknowledge the different levels at which they are triggered.

Though often excluded in the consideration of aesthetic emotion, the presentation of a text and its material design influence its haptic and visual experience. A serial publication presented in a monthly magazine or a text interspersed with drawings that prompt a multimodal reading will be experienced differently than a narrative read from a website, such as Gutenberg.org, which lacks illustrations and does not even require digitally turning a page. Though the differences might not be of quality but of degree, to do justice to the aesthetic experience, we need to consider paratextual aesthetic emotions, which might either serve or inhibit reader engagement, depending on the pleasure they take in the specific medium.

In the engagement with the text itself, it would be beneficial to distinguish more carefully between textual, intratextual, and intertextual or intermedial aesthetic emotions. Textual aesthetic emotions connect to the design of a text, its rhythm, style, and structure and are elicited by the recognition of "(non-habitual) thematically defined pattern[s]" (Hogan 13). This notion exceeds a formalist approach by acknowledging the pleasure and gratification readers take in gap-filling (following Wolfgang Iser), which Hogan refers to as "implicit beauty" (Hogan 14). Taking into account that gap-filling is shaped by readers' personal experiences, openness to experience (Silvia 2015), mood or Stimmung when encountering an aesthetic object, familiarity with specific genres, and historically, culturally, or socially determined 'emotional communities', aesthetic emotions are, to some degree, variable and will be experienced differently by different individuals.

Contrary to Menninghaus et al. (2019) and Schindler et al. (2), an analysis of aesthetic emotions in literature should also include emotions that are represented in literary works. However, I do not propose including all "art-represented emotions" (Menninghaus et al. 2019, 14), but only those related to aesthetic experiences, i.e. characters' experiences of an artwork, an aesthetic object, an event, or nature. The (reflected) existential loneliness compensated for by feelings of the sublime, experienced by Walton, Frankenstein, and his creature, or the portrait of the handsome Dorian Gray that is perceived as fascinating by its creator Basil but never presented to the reader, mark important instances in which aesthetic emotions are not only pre- but also configured. These intratextual aesthetic emotions engage readers in their 
refiguration while also creating a sense of distancing, which allows us to reflect upon the aesthetic-emotion scaffolding of a text.

Insofar as the aesthetic object responded to corresponds to a (real or literary) artwork or objects that exist beyond the narrative, I would propose to further distinguish intermedial or intertextual aesthetic emotions: Aesthetic emotions can be 'imported' into a narrative, drama, or a poem by referring to familiar dual-valence objects which activate readers' emotional knowledge. This would apply, for instance, to images of the Medusa which transport notions of both attraction and fear or repulsion, or intertextual references used by adaptations, such as Winterson's Frankissstein, which evoke aesthetic emotions through the association with the Gothic genre in general and Shelley's novel in particular.

A final example from Gothic fiction, Bram Stoker's Dracula (1897), shall serve to illustrate the interconnections of these different levels. Determined to escape Dracula's castle where he is held prisoner, Jonathan Harker notes in his diary "a wild desire took me" (Stoker 53) shortly before he describes how he searched Dracula's undead body for the key to the castle's doors. This passage alludes to the fascination and phobia surrounding Oscar Wilde, who was imprisoned for gross indecency in 1895 when Stoker was writing Dracula. However, the "wild[e] desire", which points to transgressive and, at the time, forbidden desires - "to feel another man's body" (Schaffer 399) - is presented within a safe space: Harker's experience is recollected in his diary, which is indicated by the date written above each entry in italics. It is told in retrospect, and not meant for the curious eye of the reader. This notion of safe readership, however, makes the attraction to the taboo and the forbidden - also represented on the intratextual level, heightened by the intertextual link to Oscar Wilde's supposedly immoral writings, and intensified by first-person narrative (textual) - all the more enjoyable. Furthermore, it secures the ongoing attraction of Stoker's narrative.

Interweaving theses different levels, Stoker's Dracula, like Shelley's Frankenstein, succeeds in engaging readers in complex experiences of aesthetic emotions, which are especially characteristic of Gothic literature. As suggested in this chapter, the Gothic genre is particularly invested in the emplotment and stimulation of aesthetic emotions in both a reactive and reflective mode. It builds on, exposes, and reflects upon the tensions that are constitutive of mixed emotions, such as fascination, by involving instances of emotional and cognitive disorientation that create temporary in/securities of attachment, which ultimately make coping with these complex emotions all the more pleasurable. Considering aesthetic emotions' ability 
to "motivate us to seek further sources of such satisfaction in other artworks" (Robinson 2020,

219), this might explain why the Gothic genre in particular continues to remain 'undead'.

\section{Works Cited}

Baisch, Martin. "Faszination als ästhetische Emotion im höfischen Roman." Machtvolle Gefühle, edited by Ingrid Kasten. De Gruyter, 2010, pp. 139-99.

Baumbach, Sibylle. Literature and Fascination. Palgrave, 2015.

Beermann, Ursula, Georg Hosoya, et al. 2021. "Dimensions and Clusters of Aesthetic Emotions: A Semantic Profile Analysis." Frontiers in Psychology 12.

Bell, Clive. Art. Frederick A. Stokes Company Publishers, 1914.

Bullough, Edward. "Psychical Distance." Aesthetics: Lectures and Essays. Bowes and Bowes, 1957, pp. 93-130.

Burke, Edmund. A Philosophical Enquiry into the Origin of Our Ideas of the Sublime and the Beautiful, edited by Paul Guyer, 1757. Oxford UP, 2015.

Cupchik, Gerald C. "Emotion in Aesthetics: Reactive and Reflective Models." Poetics 23, 1994: 177-88.

Degen, Andreas. Ästhetische Faszination: Die Geschichte einer Denkfigur vor ihrem Begriff. De Gruyter, 2017.

Elpidorou, Andreas. "Neglected Emotions.” The Monist 103/2, 2020, pp. 135-146.

Feagin, Susan L. "The Pleasures of Tragedy." American Philosophical Quarterly 20/1, 1983, pp. 95-104.

Frijda, Nico H., and Louise Sundarajan. "Emotion Refinement: A Theory Inspired by Chinese Poetics.” Perspectives on Psychological Science, 2/3, 2007, pp. 227-241.

Gammerl, Benno. "Emotional Styles - Concepts and Challenges." Rethinking History 16/2, 2021: 161-75.

Gould, Carol S. "Clive Bell on Aesthetic Experience and Aesthetic Truth." British Journal of Aesthetics 34/2, 1994, pp. 124-133.

Hogan, Patrick Colm. Beauty and Sublimity: A Cognitive Aesthetics of Literature and the Arts. Cambridge UP, 2016.

Korsmeyer, Carolyn. Savouring Disgust: The Foul and the Fair in Aesthetics. Oxford UP, 2011.

Larsen, Jeff T., et al. "Varieties of Mixed Emotional Experience." Current Opinion in Behavioral Sciences 15, 2017 pp. 72-76.

Lazarus, Richard S. Emotion \& Adaptation. Oxford UP, 1991.

Levine, Caroline, Forms: Whole, Rhythm, Hierarchy, Network. Princeton UP, 2015.

Marcović, Slobodan. "Components of Aesthetic Experience: Aesthetic Fascination, Aesthetic Appraisal, and Aesthetic Emotion." i-Perception, 3/1, 2012, pp. 1-17.

Menninghaus, Winfried, et al. "Aesthetic Emotions Are a Key Factor in Aesthetic Evaluation: A Reply to Skov and Nadal (2020)." American Psychological Association 127/4, 2020, 650-654.

Menninghaus, Winfried, et al. "What are Aesthetic Emotions?" Psychological Review 126/2, 2019, 171-195.

Menninghaus, Winfried, et al. "The Distancing-Embracing model of the Enjoyment of Negative Emotions in Art Reception." Behavioral and Brain Sciences 40, 2017, pp. 1-63.

Oatley, Keith. 2017. "Art as Emotional Exploration." Behavioral and Brain Sciences, vol. 40, 2017, 37-38. 
----. 1999. "Why Fiction May Be Twice as True as Fact: Fiction as Cognitive and Emotional Simulation." Review of General Psychology 3/2: 101-117.

Reagan, Andrew J, et al. "The Emotional Arcs of Stories are Dominated by Six Basic Shapes." EPJ Data Science, vol. 5, art. 31, 2016, pp. 1-12.

Robinson, Jenefer. “Aesthetic Emotions.” The Monist 103/2, 2020, pp. 205-222.

-----. “Aesthetic Digust?” Royal Institute of Philosophy Supplements, vol. 75, 2014, pp. 51-84.

Rosenwein, Barbara H. Emotional Communities in the Early Middle Ages. Cornell UP, 2006.

Schaffer, Talia. “'A Wilde Desire Took Me.' The Homoerotic History of Dracula.” ELH 61/2, pp. 381-425.

Scheer, Monique. "Are Emotions a Kind of Practice (and is That What Makes Them have a History)? A Bourdieuian Approach to Understanding Emotion." History and Theory 51/2, 2012, pp. 193-220.

Scherer, Klaus R. "What Are Emotions? And How Can They Be Measured?" Social Science Information 44/4, 2005, pp. 695-729.

Schindler, Ines, et al. "Measuring Aesthetic emotions: A Review of the Literature and a New Assessment Tool." PLoS ONE, vol. 12, art. 6, 2017, pp. 1-45.

Shelley, Mary. Frankenstein, or The Modern Prometheus, edited by Maurice Hindle, Penguin Books, 2003.

Silvia, Paul J., et al. "Openness to Experience and Awe in Response to Nature and Music: Personality and Profound Aesthetic Experiences." Psychology of Aesthetics, Creativity, and the Arts, 9/4, 2015, 376-384.

Silvia, Paul J. "Confusion and Interest: The Role of Knowledge Emotions in Aesthetic Experience." Psychology of Aesthetics, Creativity, and the Arts 4/2, 2010, pp. 75-80.

Stoker, Bram. Dracula, edited by Nina Auerbach and David J. Skal. Norton, 1997.

Wordsworth, William. "Preface". Wordsworth \& Coleridge, Lyrical Ballads, edited by R.L. Brett and A.R. Jones, Routledge 1991.

Zeki, Semir. "Clive Bell's 'Significant Form' and the Neurobiology of Aesthetics." Frontiers in Human Neuroscience, vol. 7, art. 730, pp. 1-14. 